\title{
Whole blood-derived miRNA profiles as potential new tools for ovarian cancer screening
}

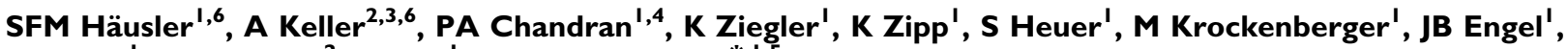 \\ A Hönig', M Scheffler' ${ }^{2}$, J Dietl' and J Wischhusen ${ }^{*, 1,5}$ \\ 'Department of Obstetrics and Gynaecology, University of Würzburg, School of Medicine, Josef-Schneider-Strasse 4, Würzburg 97080, Germany; \\ ${ }^{2}$ Febit Biomed Gmbh,Im Neuenheimer Feld 519, Heidelberg 69120, Germany; ${ }^{3}$ Biomarker Discovery Center Heidelberg, Heidelberg 69I 20, Germany; \\ ${ }^{4}$ Graduate School for Life Sciences, University of Würzburg, School of Medicine, Josef-Schneider-Strasse 4, Würzburg 97080, Germany; ${ }^{5}$ Interdisciplinary \\ Center for Clinical Research, University of Würzburg, School of Medicine, Josef-Schneider-Strasse 4, Würzburg 97080, Germany
}

\begin{abstract}
BACKGROUND: Screening is an unsolved problem for ovarian cancer (OvCA). As late detection is equivalent to poor prognosis, we analysed whether OvCA patients show diagnostically meaningful microRNA (miRNA) patterns in blood cells.

METHODS: Blood-borne whole miRNome profiles from 24 patients with OvCA and 15 age- and sex-matched healthy controls were biostatistically evaluated.

RESULTS: Student's t-test revealed 147 significantly deregulated miRNAs before and 4 after Benjamini-Hochberg adjustment. Although these included miRNAs already linked to OVCA (e.g., miR-16, miR-155), others had never before been connected to specific diseases. A bioinformatically calculated miRNA profile allowed for discrimination between blood samples of OvCA patients and healthy controls with an accuracy of $>76 \%$. When only cancers of the serous subtype were considered and compared with an extended control group $(n=39)$, accuracy, specificity and sensitivity all increased to $>85 \%$.

CONCLUSION: Our proof-of-principle study strengthens the hypothesis that neoplastic diseases generate characteristic miRNA fingerprints in blood cells. Still, the obtained OvCA-associated miRNA pattern is not yet sensitive and specific enough to permit the monitoring of disease progression or even preventive screening. Microarray-based miRNA profiling from peripheral blood could thus be combined with other markers to improve the notoriously difficult but important screening for OvCA. British Journal of Cancer (2010) 103, 693-700. doi:I0.1038/sj.bjc.6605833 www.bjcancer.com

Published online 3 August 2010

(c) 2010 Cancer Research UK
\end{abstract}

Keywords: ovarian cancer; miRNA profiles; tumour marker screening; monitoring

Patients suffering from ovarian cancer (OvCA) are still burdened by the most unfavourable prognosis of all gynaecological cancers (Pectasides and Pectasides, 2006). This is largely due to the generally late detection of the disease: while 5-year survival is $90 \%$ in those $25 \%$ of cases in which diagnosis is achieved at FIGO I stage (Duffy et al, 2005; Badgwell and Bast, 2007), long-term survival becomes very limited at advanced stages FIGO III and IV (combined 5-year survival rate $\sim 10 \%$ ) (Duffy et al, 2005). Accordingly, there is a major interest in the discovery of biomarkers for the early detection of OvCA (Clarke-Pearson, 2009). However, even CA125 that was the most promising single marker found in serum is neither sensitive nor specific enough (Meany et al, 2009) and therefore not recommended for screening of asymptomatic women (Duffy et al, 2005). Sensitivity is biologically limited by the lack of CA125 (over)expression in approximately 50\% of OvCAs at FIGO stage I (Jacobs and Bast, 1989). Specificity is also a problem because approximately $1 \%$ of all healthy women seem to have

\footnotetext{
*Correspondence: Dr J Wischhusen;

E-mail: Wischhusen_@klinik.uni-wuerzburg.de

${ }^{6}$ The first two authors contributed equally to this work.

Revised 28 June 2010; accepted 7 July 2010; published online 3 August 2010
}

elevated levels of this marker (Bast et al, 1983). In addition, several benign conditions such as endometriosis, pelvic inflammations, ovarian cysts or even pregnancy (Duffy et al, 2005) also result in increased CA125 levels.

As a tool for the monitoring of OvCA recurrence, CA125 is also of very limited use. Until now there is no evidence that an earlier initiation of suitable therapies on increases in CA125 levels translates into a prolonged survival (Eisenhauer et al, 1997). Thus, surveillance of OvCA patients with CA125 is not recommended at the moment (Duffy et al, 2005).

Considering that all efforts to identify suitable protein biomarkers were largely futile, we turned our attention to microRNAs (miRNAs). These small (17-24 nucleotides) non-coding RNAs (Lee et al, 1993) regulate many physio- and pathological processes through control of gene expression (Calin and Croce, 2006; Zhang et al, 2007). As opposed to mRNAs, miRNAs are active moieties by themselves and should thus reflect physiological alterations more directly (Gilad et al, 2008). A de-regulation of miRNA expression has already been described in numerous malignancies including OvCA in which it was functionally connected to the inhibition of apoptosis (Yang et al, 2008; Zhang et al, 2008). As tumourassociated miRNA patterns are highly tissue-specific, they can allow an identification of the origin of tumour metastases (Rosenfeld et al, 2008). Moreover, miRNAs are also remarkably 
stable which allows their easy isolation and analysis from tissues and from blood in which they can be found both as free circulating nucleic acids and in mononuclear cells (Chen et al, 2008). The possibility to analyse multiple miRNAs in parallel through nucleotide arrays further offers the possibility to increase sensitivity and specificity by using complex miRNA expression patterns as opposed to single biomarkers. Thus, miRNAs might constitute very useful and accessible diagnostic tools (Chen et al, 2008; Gilad et al, 2008). Accordingly, we used the latest and most complete collection of miRNA sequences analysed to date to identify potential differences between the blood-derived miRNA profiles of OvCA patients and healthy volunteers. On the basis of the findings of our proof-of-principle study, we suggest that this new approach holds considerable promise for the development of improved screening and surveillance strategies for OvCA.

\section{MATERIALS AND METHODS}

\section{Samples}

Blood sampling from OvCA patients and healthy controls has been approved by the local ethics committee. All donors gave written informed consent. The required cohort size was estimated by power analysis. All 24 patients (median age: 64 years, range 29-81 years) had been diagnosed with relapsed OvCA. The time elapsed since the last application of chemotherapy was sufficient to allow for a complete clearance of the drugs. Control samples were obtained from 15 age- and sex-matched volunteers without known disease (median age: 58 years, range 36-83 years). More detailed information on patients is given in Table 1.

\section{miRNA extraction and microarray screening}

Blood samples ( $5 \mathrm{ml}$ per patient) were collected in PAXgene Blood RNA tubes (BD Biosciences, Heidelberg, Germany) and frozen at $-86^{\circ} \mathrm{C}$. After thawing, cellular fractions were obtained by centrifugation $(5000 \mathrm{~g}, 10 \mathrm{~min})$, resuspended in $10 \mathrm{ml}$ RNAse-free water and subjected to total RNA isolation using the miRNeasy kit (Qiagen $\mathrm{GmbH}$, Hilden, Germany). RNA was eluted in water and shipped on dry ice to be analysed on febits Geniom real-time analyser (GRTA, febit gmbh, Heidelberg, Germany) using the Geniom Biochip miRNA homo sapiens. Each array contains 7 replicates of 904 miRNAs and miRNA star sequences as annotated in the Sanger miRBase 14.0 (Griffiths-Jones et al, 2005, 2008). Samples were biotinylated using either the miRVANA miRNA Labeling Kit (Applied Biosystems Inc., Foster City, CA USA) or by microfluidic-based enzymatic on-chip labeling of miRNAs (MPEA) (Vorwerk et al, 2008).

After hybridisation for $16 \mathrm{~h}$ at $42{ }^{\circ} \mathrm{C}$, the biochip was washed automatically and a program for signal enhancement was processed with the GRTA. Results were analysed using the Geniom Wizard Software. For each array, the median signal intensity was extracted from the raw data file such that for each miRNA seven intensity values have been calculated corresponding to each replicate copy of miRBase on the array.

After background correction, median values were calculated from the seven replicate intensity values of each miRNA. To normalise arrays, variance stabilising normalisation (VSN) (Huber et al, 2002) as implemented in the R package VSN has been applied and all further analyses were carried out using the normalised and background-subtracted intensity values. All microarray data were stored in the freely accessible miRDBXP database (http://64.119.137.93/fmi/iwp), which is designed to store any type

Table I Patient characteristics

\begin{tabular}{|c|c|c|c|c|c|}
\hline Number & $\begin{array}{l}\text { Year of } \\
\text { birth }\end{array}$ & Histology & Current therapy & Pre-therapies & $\begin{array}{l}\text { Tumour } \\
\text { load }\end{array}$ \\
\hline 1 & 1980 & Serous & $\begin{array}{l}\text { Pegylated liposomal } \\
\text { doxorubicin }\end{array}$ & Paclitaxel/carboplatin & ++ \\
\hline 2 & 1938 & Serous & Topotecan & Paclitaxel/carboplatin; carboplatin mono & ++ \\
\hline 3 & $|95|$ & Serous & Gemcitabine & $\begin{array}{l}\text { Paclitaxel/carboplatin; pegylated liposomal doxorubicin; topotecan, } \\
\text { treosulfan }\end{array}$ & ++ \\
\hline 4 & 1931 & Serous & Topotecan & Carboplatin mono & + \\
\hline 5 & 1937 & $\begin{array}{l}\text { Serous OvCA or } \\
\text { uterine carcinoma }\end{array}$ & Treosulfan & Paclitaxel/carboplatin; epirubicin; carboplatin mono & + \\
\hline 6 & 1937 & Solid & Topotecan & Cyclophosphamid/carboplatin; carboplatin mono Paclitaxel/carboplatin & + \\
\hline 7 & 1947 & Serous & Topotecan & Paclitaxel/carboplatin & ++ \\
\hline 8 & 1939 & Serous & Topotecan & Paclitaxel/carboplatin & +++ \\
\hline 9 & 1955 & Serous & $\begin{array}{l}\text { Pegylated liposomal } \\
\text { doxorubicin }\end{array}$ & Paclitaxel/carboplatin; topotecan & + \\
\hline 10 & 1931 & Serous & Paclitaxel & Carboplatin mono; topotecan; pegylated liposomal doxorubicin; treosulfan & + \\
\hline|| & 1954 & Serous & Treosulfan & $\begin{array}{l}\text { Paclitaxel/carboplatin; topotecan; carboplatin mono; pegylated liposomal } \\
\text { doxorubicin }\end{array}$ & +++ \\
\hline 12 & 1954 & Serous & Topotecan & Paclitaxel/carboplatin; pegylated liposomal doxorubicin; HIPEC with mitomycin & ++ \\
\hline 13 & 1943 & Serous & Gemcitabine & $\begin{array}{l}\text { Paclitaxel/carboplatin; peg.-lip. doxorubicin; topotecan; vinorelbin; treosulfan; } \\
\text { carboplatin mono; paclitaxel }\end{array}$ & ++ \\
\hline 14 & 1960 & Serous & Carboplatin mono & Paclitaxel/carboplatin; topotecan & + \\
\hline 15 & 1929 & Endmetrioid & Carboplatin mono & Carboplatin mono; topotecan; pegylated liposomal doxorubicin; treosulfan & + \\
\hline 16 & 1963 & Endometrioid & Paclitaxel/carboplatin & Carboplatin mono; pegylated liposomal doxorubicin; treosulfan & + \\
\hline 17 & 1929 & Serous & Treosulfan & Carboplatin mono & + \\
\hline 18 & 1940 & Serous & Topotecan & Carboplatin mono; paclitaxel/carboplatin; pegylated liposomal doxorubicin & +++ \\
\hline 19 & 1955 & Serous & $\begin{array}{l}\text { Pegylated liposomal } \\
\text { doxorubicin }\end{array}$ & Paclitaxel/carboplatin; topotecan; carboplatin mono & +++ \\
\hline 20 & 1950 & Serous & Paclitaxel & Paclitaxel/carboplatin & ++ \\
\hline 21 & 1946 & Serous & Topotecan & Carboplatin mono; pegylated liposomal carboplatin; & + \\
\hline 22 & 1965 & Serous & Paclitaxel/carboplatin & None & + \\
\hline 23 & 1963 & Serous & Paclitaxel/carboplatin & Paclitaxel/carboplatin & ++ \\
\hline 24 & 1933 & Serous & $\begin{array}{l}\text { Pegylated liposomal } \\
\text { doxorobicin }\end{array}$ & Paclitaxel/carboplatin & + \\
\hline
\end{tabular}

Abbreviations: HIPEC = hyperthermic intraoperative peritoneal chemotherapy; OVCA = ovarian cancer. Tumour load: '+': modest/ '++': high/ '+++': huge. 
of miRNA expression pattern (paper in preparation). In addition, the data have also been deposited in GEO. Additional 24 miRNA profiles from healthy controls - on the basis of a previous version of the Sanger database containing 864 miRNAs - were generously provided by Eckart Meese (University of Homburg, Germany).

\section{Statistical analysis}

The approximate normal distribution of the measured data was verified by Shapiro-Wilk test. Next, miRNAs showing a different behaviour in the two groups were identified by unpaired two-tailed parametric $t$-test. $P$-values obtained for each individual miRNA were adjusted for multiple testing by Benjamini-Hochberg (Hochberg, 1988; Benjamini et al, 2001) adjustment. In addition to the single biomarker analysis, samples were also classified according to miRNA patterns as calculated using support vector machines (SVMs, (Vapnik, 1999)) implemented in the R (Team, 2008) e1071 package. In detail, different kernel (linear, polynomial, sigmoid, radial basis function) SVMs were evaluated with the cost parameter being sampled from 0.01 to 10 in decimal powers. The measured miRNA profiles were classified using 100 repetitions of standard 10-fold cross-validation and subsets were selected according to a $t$-test-based filter approach. This means that in each repeat of the cross-validation the $s$ miRNAs with lowest $P$-values were computed on the training set Keller et al, 2006, with $s$ being sampled according to the included number of miRNAs. The respective subset was then used to train the SVM for the prediction of the test samples, which enabled a calculation of the mean accuracy, specificity and sensitivity for each subset size. Permutation tests were applied to check for overtraining. In this study, the class labels were sampled at random and classifications were carried out using the permuted class labels (Keller et al, 2006). All statistical analyses were performed using R (Wilcoxon, 1945; $\mathrm{R}$ development Core Team, 2008).

\section{RESULTS}

In total, 24 blood samples from patients suffering from relapsed OvCA were analysed. Patient characteristics are provided in Table 1. All patients had already been treated with 1-7 different chemotherapeutic schemes and were about to receive the next chemotherapeutic treatment, none was in palliative-supportive care. However, the time elapsed since the last treatment was $>5$ half-lives and should thus have been sufficient to allow for a complete metabolic clearance of the administered drugs before the blood draw. Control persons $(n=15)$ showed a similar age distribution with a median of 58 years (range from 36 to 83 years) and had no known diseases. Although all OvCA patients have to be considered as post-menopausal after initial debulking surgery, menopausal status was not assessed in the control collective.

Quantitative analysis of miRNAs and miRNA star sequences confirmed a correlation of 0.85 for biological replicates and a variance of 0.005 between these replicates. A comparison between OvCA patients and healthy controls then revealed 147 significantly $(P<0.05)$ deregulated miRNAs according to Student's unadjusted $t$-test. After adjustment for multiple comparisons by the Benjamini-Hochberg approach, expression levels of four miRNAs were still significantly different with $\mathrm{miR}-30 \mathrm{c} 1^{*}$ being upregulated in OvCA and miR-342-3p, miR-181a ${ }^{*}$ and miR-450b-5p being downregulated. To exemplify these differences, the expression levels of miR-30c1* and miR-181a* are shown in Figure $1 \mathrm{~A}$ while the receiver operator characteristics (diagram) for miR-342-3p is shown in Figure 1B. Although individual deregulated miRNAs are unlikely to serve as suitable biomarkers for OvCA (as indicated by the highest AUC value of 0.86 for miR-342-3p), they may nevertheless contain some interesting biological information relating to the disease. Thus, the 30 miRNAs that showed the strongest and most consistent deregulations between OvCA patients and healthy controls are provided in Table 2 (in order of increasing $P$-values). Of these, miR-30c- $1^{*}$, miR-191, miR-155, miR-16, miR-106b, miR-146a, miR-29a and miR-383 had already been connected to OvCA as indicated in databases linking miRNAs to specific diseases (www.mir2disease.org and http://cmbi.bjmu. edu.cn/hmdd) (Lu et al, 2008; Jiang et al, 2009). Moreover, the direction of the observed regulations (up or down) was in perfect agreement with the previously described alterations in OvCA. In total, 15 other miRNAs had, in contrast, never been linked to a specific disease at all. This observation is most likely because of the fact that our study is among the first to rely on miRBase version 14.0 (Griffiths-Jones et al, 2008) while most other studies focus on few miRNAs or on significantly smaller sets of older versions. Thus, our screening has revealed some interesting candidate miRNAs that need to be further analysed on a functional level.

To identify characteristic miRNA fingerprints that could be used for classification of the samples as OvCA or controls we used statistical learning techniques, especially SVMs with different kernels, as described above. Classification was performed as recently published (Keller et al, 2006, 2009a). 100 iterative repeats of standard 10-fold cross-validation were applied to improve statistical significance. To validate the findings, 100 repetitions were performed with permutated samples that had thus been randomly assigned to either the cancer or the control group in advance.

A radial basis function SVM achieved the best result with a subset of the 60 most significantly deregulated miRNAs (see Supplementary Table S1). The classification of the blood samples as 'OvCA' respective 'control group' was carried out with an accuracy of $76.3 \%$, a specificity of $83.0 \%$ and a sensitivity of $69.7 \%$ (Figure 2A). The permutation tests with randomly given class labels showed clearly lower accuracy $(40.1 \%)$, sensitivity $(36.8 \%)$ and specificity $(41.8 \%)$ (Figure $2 \mathrm{~A}$ ), which confirms that the above-mentioned values are not achieved by random guessing. Moreover, when the data from all serous OvCAs $(n=20)$ were compared with an extended standard control cohort consisting of individuals without known affection $(n=39), 40$ miRNAs and 100 repetitions sufficed to obtain an accuracy, a specificity and a sensitivity of $\geqslant 85 \%$ (Figure $2 \mathrm{~B}$ ), indicating the potential of our approach. As the OvCA group additionally showed miRNA patterns that differ from published profiles for lung cancer (Keller et al, 2009a), melanoma (Leidinger et al, 2010) or multiple sclerosis (Keller et al, 2009b) and from yet unpublished ones for pancreatic cancer, prostate cancer, Wilms' tumours, pancreatitis, chronic obstructive pulmonary disease, peridontitis, sarkoidosis, heart attacks and unclassified pancreatic diseases (data not shown), our study shows for the first time that OvCA patients show characteristic miRNA signatures in peripheral blood.

\section{DISCUSSION}

In this study, we show that the expression of multiple miRNAs is significantly altered in the blood of OvCA patients as compared with healthy controls. Many of these have never been connected to specific diseases before while eight (miR-30c- ${ }^{*}$, miR-191, miR-155, miR-16, miR-106b, miR-146a, miR-29a and miR-383) have already been described in the context of OvCA. This may partly be due to the fact that our chip contained many miRNAs that had not been analysed before. Clearly, further studies will be required to elucidate functional consequences of altered miRNA levels in the blood of OvCA patients.

Our study did not follow the current trend to investigate circulating miRNAs in serum from cancer patients (Lodes et al, 2009) but rather included the cellular fraction as well. Thus, tumour-specific miRNA profiles contained in exosomes may partly 
be masked (or, at least, 'diluted') by the greater amount of cellular miRNAs. However, experiments performed on lung cancer patients before this study revealed that this is over-compensated

A
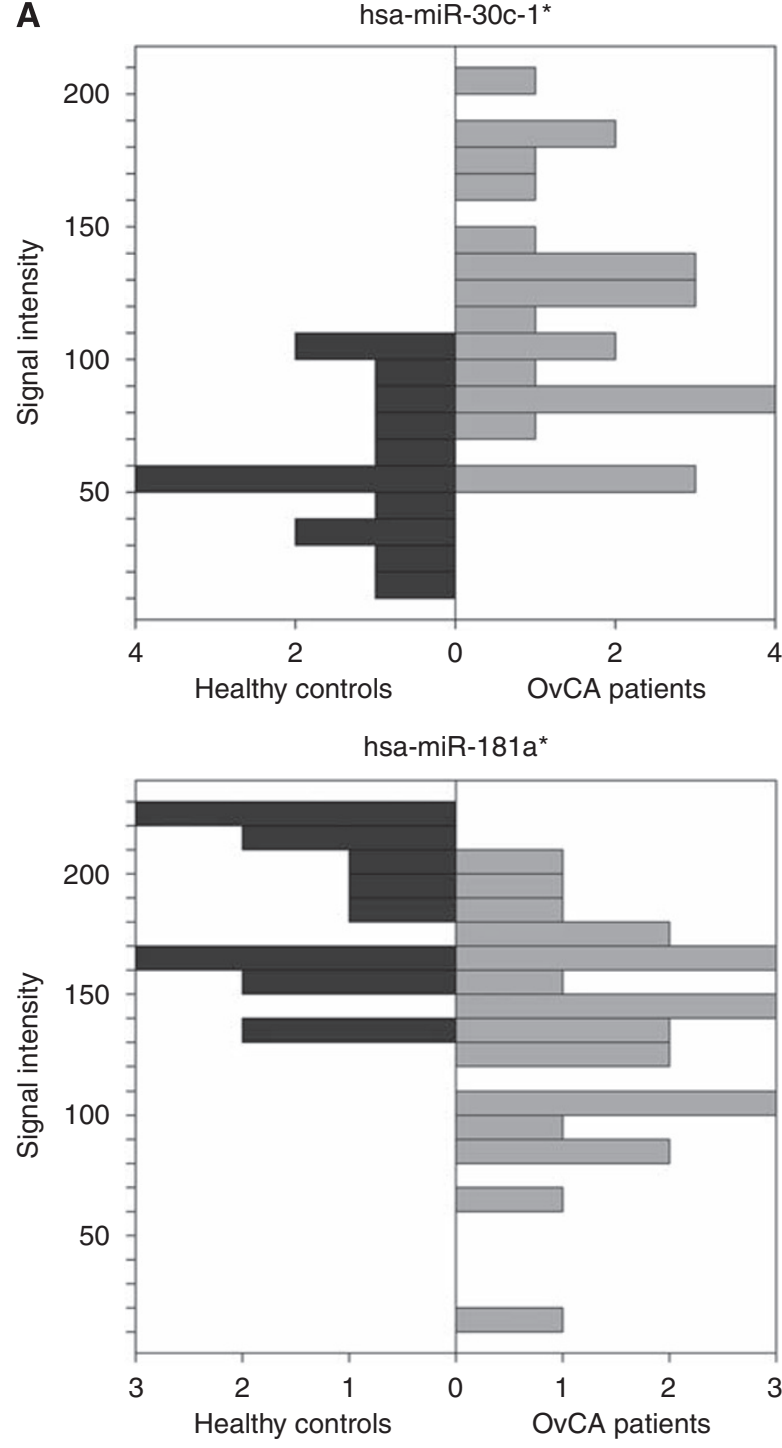

B

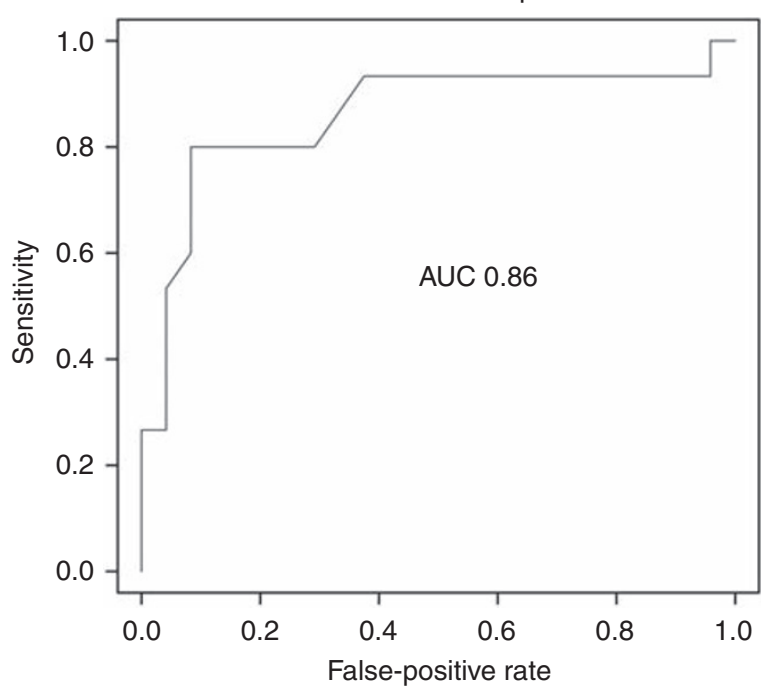

by the information contained in the cellular fraction. As the frequency of circulating tumour cells is low in OvCA (median:

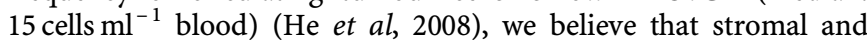
myeloid progenitors (Marigo et al, 2008; Tu et al, 2008) or regulatory $\mathrm{T}$ cells, which are recruited to the tumour site (Curiel et al, 2004) may significantly contribute to these profiles. Similarly, immunosuppressive and pro-angiogenic signals sent out by the tumour may leave their marks in blood cells. Considering that the formation of a pre-metastatic niche by hematopoietic cells is an early event in tumourigenesis and metastasis (Kaplan et al, 2005), it even seems plausible that 'imprinted' profiles from blood cells may already be detectable at very early stages of tumour development - whereas miRNAs that are released from cancer cells will only become detectable once a significant neoplastic mass has accumulated.

On the basis of the present data, blood samples from OvCA patients are likely to contain information that can be diagnostically exploited through the combination of microarray-based analysis of complex miRNA fingerprints and statistical learning approaches. Importantly, the profiles obtained for our OvCA collective are clearly distinct from profiles obtained by other centres from patients with lung cancer, prostate cancer, melanoma, pancreatic cancer, Wilms' tumours, pancreatitis, chronic obstructive pulmonary disease, peridontitis, sarkoidosis, heart attacks, multiple sclerosis and unclassified pancreatic diseases (data not shown), which strongly suggests that the observed patterns are indeed disease-specific and not because of nonspecific systemic inflammatory processes or therapy-related toxicity. Thus, a further development of the present approach clearly holds some promise.

At the current stage, however, the predictive power achieved by our proof-of-principle study is too low for a population-wide clinical screening and the values computed for accuracy, specificity and sensitivity could not match those obtained with slightly bigger patient cohorts for lung cancer (Keller et al, 2009a) or multiple sclerosis (Keller et al, 2009b). Thus, the positive predictive value (PPV), which was $80.4 \%$ for our collective would drop to $0.3 \%$ if the test was applied to the general population (assuming an annual incidence of 40 OvCA cases in $10^{5}$ women over 50 years). However, while this is clearly insufficient, preselection of a clinically relevant risk population such as BRCA1 or BRCA2 mutation carriers (Antoniou et al, 2003, 2008) could raise the PPV to $\geqslant 10 \%$ without further optimisation, simply because of the higher prevalence in this collective. Moreover, the negative predictive value would still be $99.8 \%$ for such a collective, which compares fairly well with other markers described for OvCA.

From an economic perspective, miRNA profiling from serum seems rather attractive for clinical diagnostics. Although a wealth of information may be gained for many different conditions, the cost for a single experiment amounts is below US \$ 200 (with in-house data generation and analysis). Considering that this allows the measurement of over $900 \mathrm{miRNas}$ in seven replicates, a single data point costs approximately US $\$ 0.03$.

One limitation of this study is certainly the very restricted size of the study collective that makes the results sensitive to individual

Figure I Deregulation of miR-30c- I ${ }^{*}$ and miR- $181 \mathrm{a}^{*}$ in OvCA samples compared with healthy controls. (A) Shown are the intensities of expression for miR-30c-I* (upper panel) and miR-I8Ia* (middle panel) in blood samples from healthy donors (dark grey, $n=15$ ) or OVCA patients (light grey, $n=24)$. $P$ values (OvCA vs control) were 0.01 for miR$30 \mathrm{c}-{ }^{*}$ and 0.04 for miR-181a*, as calculated by Student's unpaired twotailed parametric $t$-test followed by the Benjamini-Hochberg adjustment for multiple comparisons. (B) Receiver operating characteristics (ROC) were generated to show how the sensitivity of OVCA detection and the rate of false positives vary with the discrimination threshold for single miRNAs. Shown is the ROC curve for miR-342-3p. AUC denotes the area under the curve, which is equal to the probability that a classification based on miRNA-342-3p will rank a randomly chosen positive sample higher than a randomly chosen negative one. 
Table 2 miRNAs showing differential expression between OvCA samples and negative controls

\begin{tabular}{|c|c|c|c|c|c|c|}
\hline & $\begin{array}{l}\text { Ovarian } \\
\text { cancer }\end{array}$ & Control & $\begin{array}{l}\text { Relative } \\
\text { expression }\end{array}$ & $P$-value & $\begin{array}{l}\text { Adjusted } \\
\text { P-value }\end{array}$ & $\begin{array}{l}\text { Related diseases according www.mir2disease.org } \\
\text { (Jiang et al, 2009) and HMDD (Lu et al, 2008) }\end{array}$ \\
\hline miR-30c- ${ }^{*}$ & 109.59 & 44.38 & 2.50 & 0.00001 & 0.01 & $\begin{array}{l}\text { Breast cancer, colon cancer, glomeruosclerosis, heart failure, hepatocellular cancer, } \\
\text { OvCA, pancreatic cancer, prostate cancer }\end{array}$ \\
\hline$m i R-181 a^{*}$ & 139.90 & 187.08 & 0.75 & 0.0002 & 0.04 & Oral squamous cell carcinoma \\
\hline miR-450-5p & 79.95 & 137.78 & 0.58 & 0.0002 & 0.04 & None \\
\hline miR-616* & 91.24 & 153.97 & 0.59 & 0.0004 & 0.06 & None \\
\hline miR-574-5p & 2378.73 & 731.16 & 3.23 & 0.0006 & 0.06 & None \\
\hline$m i R-1228^{*}$ & 2390.13 & 1389.96 & 1.72 & 0.0007 & 0.06 & Malignant mesothelioma \\
\hline miR- $\mid 91$ & 16201.90 & 10391.60 & 1.56 & 0.0007 & 0.06 & $\begin{array}{l}\text { Colon cancer, gastric cancer, lung cancer, melanoma, ovarian cancer, pancreatic cancer, } \\
\text { prostate cancer }\end{array}$ \\
\hline miR-1915 & 1078.22 & 755.35 & 1.43 & 0.0007 & 0.06 & None \\
\hline miR-1908 & 1833.26 & 1144.19 & 1.61 & 0.0009 & 0.06 & None \\
\hline miR- $\mid 181$ & 327.24 & 238.29 & 1.37 & 0.0009 & 0.06 & Hepatitis C \\
\hline miR-16 & 21782.51 & 18702.10 & 1.16 & 0.0011 & 0.06 & $\begin{array}{l}\mathrm{CLL}, \mathrm{CML} \text {, heart failure, gastric cancer, glioma, hepatocellular carcinoma, Hodgkińs } \\
\text { lymphoma, mantle-cell lymphoma, myeloma, non-small cell lung cancer, oral squamous } \\
\text { cell cancer, ovarian cancer, papillary thyroid carcinoma, pituitary neoplasms, } \\
\text { Polycythemia vera, prostate cancer, renal cell carcinoma, ulcerative colitis, uterine } \\
\text { cervical neoplasms }\end{array}$ \\
\hline miR-106b & 6468.68 & 10391.60 & 0.62 & 0.0012 & 0.06 & $\begin{array}{l}\text { Adrenocortical carcinoma, Alzheimer's disease, autism spectrum disorders, breast } \\
\text { cancer, CLL, colorectal cancer, gastric cancer, glioma, heart failure, hepatocellular } \\
\text { carcinoma, kidney cancer, multiple myeloma, melanoma, ovarian cancer, pervasive child } \\
\text { development disorders, prostate cancer, schizophrenia, squamous cell carcinoma }\end{array}$ \\
\hline miR- 1254 & 238.33 & 179.68 & 1.33 & 0.0023 & 0.08 & None \\
\hline miR-628-5p & $|48.2|$ & 212.38 & 0.70 & 0.0024 & 0.08 & Head and neck squamous cell carcinoma \\
\hline miR-1287 & 93.37 & 123.87 & 0.75 & 0.0024 & 0.08 & None \\
\hline $\operatorname{miR}-29 a$ & 837.00 & 1175.70 & 0.71 & 0.0029 & 0.09 & $\begin{array}{l}\text { Alzheimer's disease, acquired immunodeficiency syndrome, breast cancer, cardiac } \\
\text { hypertrophy, cerebellar neurodegeneration, CLL, colorectal cancer, Duchenne muscular } \\
\text { dystrophy, FSHD, heart failure, homozygous sickle-cell disease, Huntingtońs disease, } \\
\text { lung cancer, kidney cancer, neuroblastoma, oral squamous cell carcinoma, ovarian } \\
\text { cancer, precursor cell lymphoblastic leukaemia, prostate cancer, schizophrenia }\end{array}$ \\
\hline miR-383 & 165.57 & 115.30 & 1.43 & 0.0032 & 0.10 & Azoospermia, breast cancer, chronic pancreatitis, melanoma, ovarian cancer \\
\hline miR- 1253 & 183.16 & 137.78 & 1.33 & 0.0037 & 0.11 & None \\
\hline
\end{tabular}

Abbreviations: $\mathrm{ALL}=$ acute lymphocytic leukaemia; $\mathrm{AML}=$ acute myelogenous leukaemia; $\mathrm{APL}=$ acute promyelocytic leukaemia; $\mathrm{CML}=$ chronic myelogenous leukaemia; $\mathrm{CLL}=$ chronic lymphocytic leukaemia; $\quad \mathrm{SSHD}=$ facio-scapulohumeral muscular dystrophy; HMDD = human microRNA disease database; miRNA=microRNA; OVCA = ovarian cancer. Annotation: columns 'ovarian cancer' and 'control' show median values and the relative expression OvCA vs control is obtained by taking their ratio. Upregulated miRNAs are highlighted in grey, whereas downregulated ones are plain. $P$-values were calculated using Student's $t$-test, adjusted $P$-values were determined according to the method by Benjamini and Hochberg.

outliers. In fact, when the miRNA profiles obtained from OvCA patients are compared with the summarised healthy controls from the lung cancer (Keller et al, 2009a), the multiple sclerosis (Keller et al, 2009b) and our study, accuracy, sensitivity and specificity were significantly increased (data not shown). Biological limitations may further originate from the fact that ovarian carcinomas are very heterogeneous with regard to their histopathological and molecular characteristics (Tinelli et al, 2009). Therefore, it might be desirable to establish specific miRNA fingerprints for the individual subtypes of OvCA rather than 

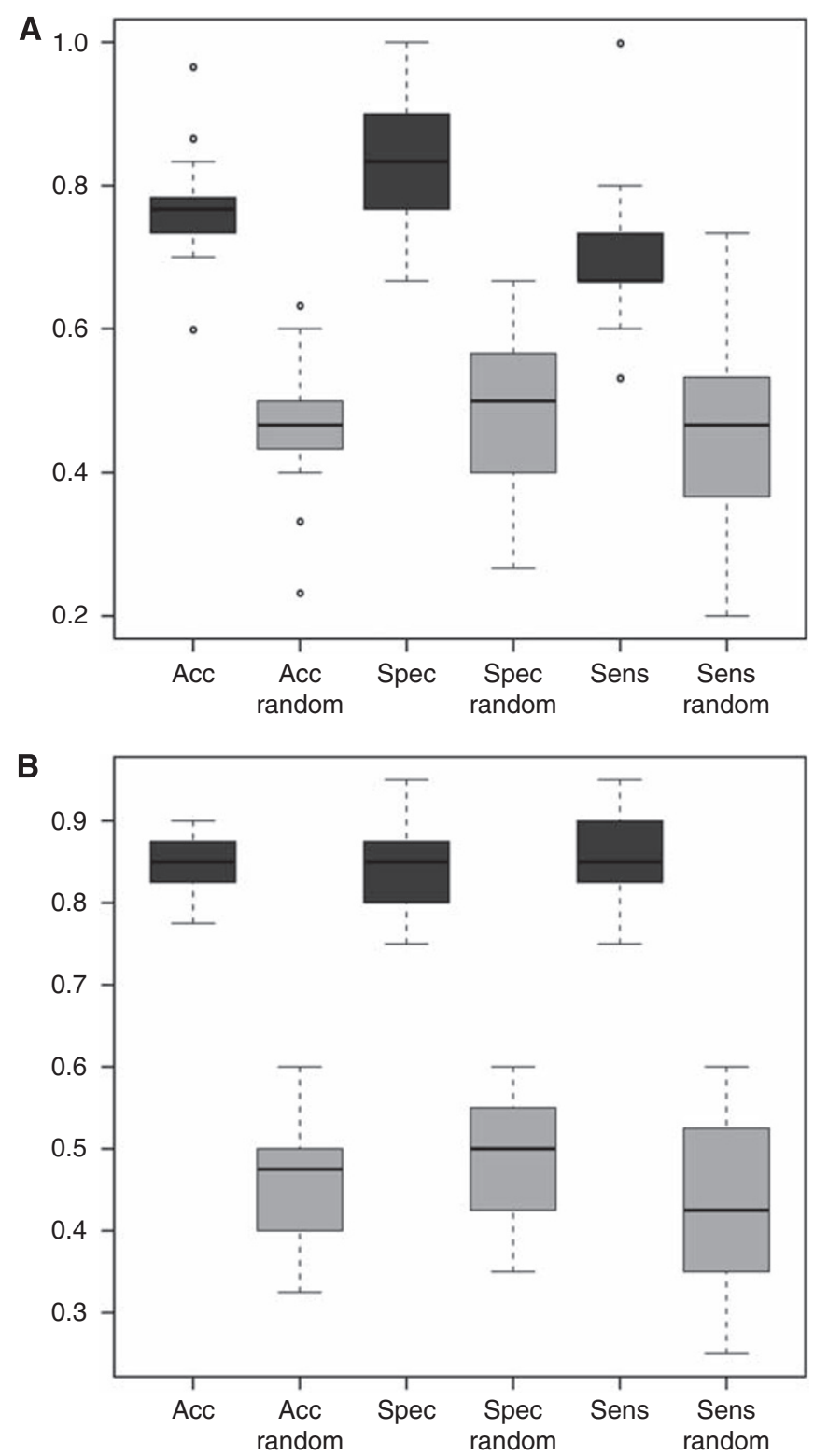

Figure 2 Classification of samples from OvCA patients or healthy controls. (A) This classification plot that is based on 60 miRNAs was computed using a radial basis function SVM as described in (Keller et al, 2006, 2009a). The black boxes showing the accuracy ('acc'), specificity ('spec') and sensitivity ('sens') for classification of all OvCA and control samples ( $n=24$ for OvCA, $n=15$ for controls) and were calculated through 100 repetitions of 10 -fold cross-validation. The grey boxes show the results obtained when the same mathematical operation is performed in permutation tests ('random') in which the class labels (OvCA vs control) have been assigned randomly before the values are computed. This is used to validate the classification procedure. The ordinate shows the proportion of samples that were classified correctly to their group. (B) Serous OvCA $(n=20)$ were compared with an extended group of healthy controls $(n=39)$ as in $(\mathbf{A})$, using 100 repetitions and 40 miRNAs.

aiming at a general approach (Köbel et al, 2008). This was corroborated by a high variance that we observed within the OvCA group. Consequently, accuracy (87.4\%), specificity (88.1) and sensitivity $(86.7 \%)$ were greatly increased when only serous OvCAs were compared with an extended control group. Still, the investigation of miRNA profiles in a large number of samples from all subtypes of OvCA was clearly beyond the scope of our pilot study.
A second factor that might have added to the variance in both groups was age. Own unpublished observations show that elderly people show significantly altered including miRNA profiles. Consequently, stratification by age groups and menopausal status might improve the distinction between healthy and diseased individuals. Again, this would require a larger study cohort.

For practical reasons, we had chosen patients suffering from a securely diagnosed OvCA as a starting point. However, while the high tumour load in these patients might help the detection of cancer-associated miRNA fingerprints, we could only select treatment-free intervals after platinum-containing therapies for the blood draws. No corrections could be made for the individually adapted treatments the patients had received before their inclusion in our study (compare Table 1), which might introduce a further confounding factor. Considering that all patients had shown progression under previous treatments, the finding by Rui et al (2009) that the development of chemoresistance goes along with changes in the miRNA profile of cancer cells might be relevant. Thus, the different therapeutic histories could also contribute to the considerable variance observed in this study. Consequently, stratification according to past treatments might greatly improve sensitivity and specificity for the monitoring of OvCA recurrence through blood-derived miRNA profiles. Alternatively, the link between miRNA fingerprints and chemotherapeutic resistance could also help to find individual and optimal therapeutic regimens for each patient. These issues clearly warrant further investigation, in particular a comparison with treatment-naïve patients (which will be performed in the course of an ongoing study). However, while Rui et al described six miRNAs that showed > two-fold alterations on chemotherapy and development of resistance, none of these were among the 30 most significantly deregulated miRNAs in our data set, which strongly suggests that we detected an OvCA-specific rather than a treatment-induced miRNA fingerprint.

Obviously, numerous questions are not answered by our proofof-principle study and remain to be addressed in follow-on studies. However, our first data already suggest that OvCA samples are associated with characteristic miRNA patterns in peripheral blood. Compared with investigated markers such as CA125, which is neither sensitive nor specific enough for OvCA screening (Duffy et al, 2005) or monitoring (Eisenhauer et al, 1997), miRNA profiling from peripheral blood seems promising, especially because many possibilities for optimisation remain. Moreover, this new non-invasive strategy could easily be combined with the best current options like the combination of the serum biomarker CA125 with transvaginal ultrasound (Menon et al, 2009) or serial determinations of CA125-levels in peripheral blood (Skates et al, 2003), which on their own are still not good enough to be recommended for use in clinical routine (Mutch, 2009; Partridge et al, 2009). Thus, we believe that the detection of OvCA-associated miRNAs from peripheral blood can become a valuable addition to the current insufficient panel of biomarkers.

\section{ACKNOWLEDGEMENTS}

This work was supported in parts by funding of the German Ministry of Research Education (BMBF) under contract 01EX0806. Additional support was provided by a grant from the IZKF Würzburg to JW.

\section{Conflict of interest}

$\mathrm{AK}$ and MS are also affiliates of febit biome $\mathrm{GmbH}$ as Vice President and Vice President of sales, respectively. The remaining authors declare no conflict of interest.

Supplementary Information accompanies the paper on British Journal of Cancer website (http://www.nature.com/bjc) 


\section{REFERENCES}

Antoniou A, Pharoah PD, Narod S, Risch HA, Eyfjord JE, Hopper JL, Loman $\mathrm{N}$, Olsson $\mathrm{H}$, Johannsson $\mathrm{O}$, Borg A, Pasini B, Radice $\mathrm{P}$, Manoukian S, Eccles DM, Tang N, Olah E, Anton-Culver H, Warner E, Lubinski J, Gronwald J, Gorski B, Tulinius H, Thorlacius S, Eerola H, Nevanlinna H, Syrjakoski K, Kallioniemi OP, Thompson D, Evans C, Peto J, Lalloo F, Evans DG, Easton DF (2003) Average risks of breast and ovarian cancer associated with BRCA1 or BRCA2 mutations detected in case series unselected for family history: a combined analysis of 22 studies. Am J Hum Genet 72: 1117-1130

Antoniou AC, Cunningham AP, Peto J, Evans DG, Lalloo F, Narod SA, Risch HA, Eyfjord JE, Hopper JL, Southey MC, Olsson H, Johannsson O, Borg A, Pasini B, Radice P, Manoukian S, Eccles DM, Tang N, Olah E, Anton-Culver H, Warner E, Lubinski J, Gronwald J, Gorski B, Tryggvadottir L, Syrjakoski K, Kallioniemi OP, Eerola H, Nevanlinna H, Pharoah PD, Easton DF (2008) The BOADICEA model of genetic susceptibility to breast and ovarian cancers: updates and extensions. Br J Cancer 98: 1457 - 1466

Badgwell D, Bast Jr RC (2007) Early detection of ovarian cancer. Dis Markers 23: $397-410$

Bast Jr RC, Klug TL, St John E, Jenison E, Niloff JM, Lazarus H, Berkowitz RS, Leavitt T, Griffiths CT, Parker L, Zurawski Jr VR, Knapp RC (1983) A radioimmunoassay using a monoclonal antibody to monitor the course of epithelial ovarian cancer. $N$ Engl J Med 309: 883-887

Benjamini Y, Drai D, Elmer G, Kafkafi N, Golani I (2001) Controlling the false discovery rate in behavior genetics research. Behav Brain Res 125: $279-284$

Calin GA, Croce CM (2006) MicroRNA signatures in human cancers. Nat Rev Cancer 6: $857-866$

Chen X, Ba Y, Ma L, Cai X, Yin Y, Wang K, Guo J, Zhang Y, Chen J, Guo X, Li Q, Li X, Wang W, Zhang Y, Wang J, Jiang X, Xiang Y, Xu C, Zheng P, Zhang J, Li R, Zhang H, Shang X, Gong T, Ning G, Wang J, Zen K, Zhang J, Zhang CY (2008) Characterization of microRNAs in serum: a novel class of biomarkers for diagnosis of cancer and other diseases. Cell Res 18: $997-1006$

Clarke-Pearson DL (2009) Clinical practice. Screening for ovarian cancer. $N$ Engl J Med 361: $170-177$

Curiel TJ, Coukos G, Zou L, Alvarez X, Cheng P, Mottram P, EvdemonHogan M, Conejo-Garcia JR, Zhang L, Burow M, Zhu Y, Wei S, Kryczek I, Daniel B, Gordon A, Myers L, Lackner A, Disis ML, Knutson KL, Chen L, Zou W (2004) Specific recruitment of regulatory $\mathrm{T}$ cells in ovarian carcinoma fosters immune privilege and predicts reduced survival. Nat Med 10: $942-949$

Duffy MJ, Bonfrer JM, Kulpa J, Rustin GJ, Soletormos G, Torre GC, Tuxen MK, Zwirner M (2005) CA125 in ovarian cancer: European group on tumor markers guidelines for clinical use. Int J Gynecol Cancer 15: 679-691

Eisenhauer EA, Vermorken JB, van Glabbeke M (1997) Predictors of response to subsequent chemotherapy in platinum pretreated ovarian cancer: a multivariate analysis of 704 patients [see comments]. Ann Oncol 8: $963-968$

Gilad S, Meiri E, Yogev Y, Benjamin S, Lebanony D, Yerushalmi N, Benjamin H, Kushnir M, Cholakh H, Melamed N, Bentwich Z, Hod M, Goren Y, Chajut A (2008) Serum microRNAs are promising novel biomarkers. PLoS One 3: e3148

Griffiths-Jones S, Moxon S, Marshall M, Khanna A, Eddy SR, Bateman A (2005) Rfam: annotating non-coding RNAs in complete genomes. Nucleic Acids Res 33: D121 - D124

Griffiths-Jones S, Saini HK, van Dongen S, Enright AJ (2008) miRBase: tools for microRNA genomics. Nucleic Acids Res 36: D154-D158

He W, Kularatne SA, Kalli KR, Prendergast FG, Amato RJ, Klee GG, Hartmann LC, Low PS (2008) Quantitation of circulating tumor cells in blood samples from ovarian and prostate cancer patients using tumorspecific fluorescent ligands. Int J Cancer 123: $1968-1973$

Hochberg Y (1988) A sharper Bonferroni procedure for multiple tests of significance. Biometrika 75: $800-802$

Huber W, von Heydebreck A, Sultmann H, Poustka A, Vingron M (2002) Variance stabilization applied to microarray data calibration and to the quantification of differential expression. Bioinformatics 18(Suppl 1): S96-S104

Jacobs I, Bast Jr RC (1989) The CA 125 tumour-associated antigen: a review of the literature. Hum Reprod 4: 1-12

Jiang Q, Wang Y, Hao Y, Juan L, Teng M, Zhang X, Li M, Wang G, Liu Y (2009) miR2Disease: a manually curated database for microRNA deregulation in human disease. Nucleic Acids Res 37: D98-D104
Kaplan RN, Riba RD, Zacharoulis S, Bramley AH, Vincent L, Costa C, MacDonald DD, Jin DK, Shido K, Kerns SA, Zhu Z, Hicklin D, Wu Y, Port JL, Altorki N, Port ER, Ruggero D, Shmelkov SV, Jensen KK, Rafii S, Lyden D (2005) VEGFR1-positive haematopoietic bone marrow progenitors initiate the pre-metastatic niche. Nature 438: 820 - 827 Keller A, Leidinger P, Borries A, Wendschlag A, Wucherpfennig F, Scheffler M, Huwer H, Lenhof HP, Meese E (2009a) miRNAs in lung cancer-studying complex fingerprints in patient's blood cells by microarray experiments. BMC Cancer 9: 353

Keller A, Leidinger P, Lange J, Borries A, Schroers H, Scheffler M, Lenhof HP, Ruprecht K, Meese E (2009b) Multiple sclerosis: microRNA expression profiles accurately differentiate patients with relapsing-remitting disease from healthy controls. PLoS One 4: e7440

Keller A, Ludwig N, Comtesse N, Hildebrandt A, Meese E, Lenhof HP (2006) A minimally invasive multiple marker approach allows highly efficient detection of meningioma tumors. BMC Bioinformatics 7: 539

Köbel M, Kalloger SE, Boyd N, McKinney S, Mehl E, Palmer C, Leung S, Bowen NJ, Ionescu DN, Rajput A, Prentice LM, Miller D, Santos J, Swenerton K, Gilks CB, Huntsman D (2008) Ovarian carcinoma subtypes are different diseases: implications for biomarker studies. PLoS Med 5: e232

Lee RC, Feinbaum RL, Ambros V (1993) The C elegans heterochronic gene lin-4 encodes small RNAs with antisense complementarity to lin-14. Cell 75: $843-854$

Leidinger P, Keller A, Borries A, Reichrath J, Rass K, Jager SU, Lenhof HP, Meese E (2010) High-throughput miRNA profiling of human melanoma blood samples. BMC Cancer 10: 262

Lodes MJ, Caraballo M, Suciu D, Munro S, Kumar A, Anderson B (2009) Detection of cancer with serum miRNAs on an oligonucleotide microarray. PLoS One 4: e6229

Lu M, Zhang Q, Deng M, Miao J, Guo Y, Gao W, Cui Q (2008) An analysis of human microRNA and disease associations. PLoS One 3: e3420

Marigo I, Dolcetti L, Serafini P, Zanovello P, Bronte V (2008) Tumorinduced tolerance and immune suppression by myeloid derived suppressor cells. Immunol Rev 222: $162-179$

Meany DL, Sokoll LJ, Chan DW (2009) Early detection of cancer: immunoassays for plasma tumor markers. Expert Opin Med Diagn 3: $597-605$

Menon U, Gentry-Maharaj A, Hallett R, Ryan A, Burnell M, Sharma A, Lewis S, Davies S, Philpott S, Lopes A, Godfrey K, Oram D, Herod J, Williamson K, Seif MW, Scott I, Mould T, Woolas R, Murdoch J, Dobbs S, Amso NN, Leeson S, Cruickshank D, McGuire A, Campbell S, Fallowfield L, Singh N, Dawnay A, Skates SJ, Parmar M, Jacobs I (2009) Sensitivity and specificity of multimodal and ultrasound screening for ovarian cancer, and stage distribution of detected cancers: results of the prevalence screen of the UK Collaborative Trial of Ovarian Cancer Screening (UKCTOCS). Lancet Oncol 10: $327-340$

Mutch DG (2009) Ovarian cancer: to screen or not to screen. Obstet Gynecol 113: $772-774$

Partridge E, Kreimer AR, Greenlee RT, Williams C, Xu JL, Church TR, Kessel B, Johnson CC, Weissfeld JL, Isaacs C, Andriole GL, Ogden S, Ragard LR, Buys SS (2009) Results from four rounds of ovarian cancer screening in a randomized trial. Obstet Gynecol 113: $775-782$

Pectasides D, Pectasides E (2006) Maintenance or consolidation therapy in advanced ovarian cancer. Oncology 70: 315-324

$\mathrm{R}$ developmental Core Team RDC (2008) R: A Language and Environment for Statistical Computing. Vol. 3, R Foundation for Statistical Computing: Vienna, Austria

Rosenfeld N, Aharonov R, Meiri E, Rosenwald S, Spector Y, Zepeniuk M, Benjamin H, Shabes N, Tabak S, Levy A, Lebanony D, Goren Y, Silberschein E, Targan N, Ben-Ari A, Gilad S, Sion-Vardy N, Tobar A, Feinmesser M, Kharenko O, Nativ O, Nass D, Perelman M, Yosepovich A, Shalmon B, Polak-Charcon S, Fridman E, Avniel A, Bentwich I, Bentwich Z, Cohen D, Chajut A, Barshack I (2008) MicroRNAs accurately identify cancer tissue origin. Nat Biotechnol 26: $462-469$

Rui W, Bing F, Hai-Zhu S, Wei D, Long-Bang C (2009) Identification of microRNA profiles in docetaxel-resistant human non-small cell lung carcinoma cells (SPC-A1). J Cell Mol Med 9: 9

Skates SJ, Menon U, MacDonald N, Rosenthal AN, Oram DH, Knapp RC, Jacobs IJ (2003) Calculation of the risk of ovarian cancer from serial CA-125 values for preclinical detection in postmenopausal women. J Clin Oncol 21: 206s-210s 
Tinelli A, Vergara D, Martignago R, Leo G, Pisano M, Malvasi A (2009) An outlook on ovarian cancer and borderline ovarian tumors: focus on genomic and proteomic findings. Curr Genomics 10: 240-249

Tu S, Bhagat G, Cui G, Takaishi S, Kurt-Jones EA, Rickman B, Betz KS, PenzOesterreicher M, Bjorkdahl O, Fox JG, Wang TC (2008) Overexpression of interleukin-1beta induces gastric inflammation and cancer and mobilizes myeloid-derived suppressor cells in mice. Cancer Cell 14: 408-419

Vapnik V (1999) The Nature of Statistical Learning Theory (Information Science and Statistics). Springer: New York, NY, USA.

Vorwerk S, Ganter K, Cheng Y, Hoheisel J, Stahler PF, Beier M (2008) Microfluidic-based enzymatic on-chip labeling of miRNAs. N Biotechnol 25: $142-149$

Wilcoxon F (1945) Individual comparisons by ranking methods. Biometrics Bull 1: $80-83$
Yang H, Kong W, He L, Zhao JJ, O’Donnell JD, Wang J, Wenham RM, Coppola D, Kruk PA, Nicosia SV, Cheng JQ (2008) MicroRNA expression profiling in human ovarian cancer: miR-214 induces cell survival and cisplatin resistance by targeting PTEN. Cancer Res 68: 425-433

Zhang B, Pan X, Cobb GP, Anderson TA (2007) microRNAs as oncogenes and tumor suppressors. Dev Biol 302: $1-12$

Zhang L, Volinia S, Bonome T, Calin GA, Greshock J, Yang N, Liu CG, Giannakakis A, Alexiou P, Hasegawa K, Johnstone CN, Megraw MS, Adams S, Lassus H, Huang J, Kaur S, Liang S, Sethupathy P, Leminen A, Simossis VA, Sandaltzopoulos R, Naomoto Y, Katsaros D, Gimotty PA, DeMichele A, Huang Q, Butzow R, Rustgi AK, Weber BL, Birrer MJ, Hatzigeorgiou AG, Croce CM, Coukos G (2008) Genomic and epigenetic alterations deregulate microRNA expression in human epithelial ovarian cancer. Proc Natl Acad Sci USA 105: 7004-7009 